\title{
polymers
}

ISSN 2073-4360

www.mdpi.com/journal/polymers

Article

\section{Functionalization, Compatibilization and Properties of Polyolefin Composites with Natural Fibers}

\author{
Mariano Pracella $^{1} *$, Md. Minhaz-Ul Haque ${ }^{2}$ and Vera Alvarez ${ }^{3}$
}

1 Institute of Composite and Biomedical Materials, IMCB- CNR, Via Diotisalvi 2, Pisa 56122, Italy

2 Department of Chemical Engineering, Industrial Chemistry and Materials Science, University of Pisa, Pisa 56122, Italy; E-Mail: minhaz1978@yahoo.com

3 Polymer Division, INTEMA-CONICET, University of Mar del Plata, Mar del Plata, Argentina; E-Mail: alvarezvera@fi.mdp.edu.ar

* Author to whom correspondence should be addressed; E-Mail: mariano.pracella@ diccism.unipi.it; Tel.: +39-0502217829; Fax: +39-0502217866.

Received: 14 October 2010; in revised form: 2 November 2010 / Accepted: 10 November 2010 / Published: 15 November 2010

\begin{abstract}
The article is focused on analyzing the effect of functionalization and reactive processing on the morphological, thermal, rheological and mechanical properties of composites of isotactic polypropylene (PP), polystyrene (PS), poly(ethylene-vinyl acetate) (EVA), with cellulose fibers, hemp or oat as natural fillers. Both polymers and fibers were modified with bi-functional monomers (glycidyl methacrylate, GMA; maleic anhydride, MA) capable of facilitating chemical reactions between the components during melt mixing. Polyolefin copolymers containing reactive groups (PP-g-GMA, SEBS-g-MA, PS-co-MA, etc.) were used as compatibilizers. Optical and SEM microscopy, FTIR, RX, DSC, TGA, DMTA, rheological and mechanical tests were employed for the composites characterization. The properties of binary and ternary systems have been analyzed as a function of both fiber and compatibilizer content. All compatibilized systems showed enhanced fiber dispersion and interfacial adhesion. The phase behavior and the thermal stability of the composites were affected by the chemical modification of the fibers. Marked changes in the overall crystallization processes and crystal morphology of PP composites were observed owing to the nucleating effect of the fibers. The tensile mechanical behavior of the compatibilized composites generally resulted in a higher stiffness, depending on the fiber amount and the structure and concentration of compatibilizer.
\end{abstract}


Keywords: polymer composites; natural fibers; functionalization; compatibilization; morphology; physical-mechanical properties

\section{Introduction}

Polymer composites based on natural fillers are currently receiving great attention as innovative materials for industrial applications in several sectors, such as automotive, building, appliance, packaging and biomaterials. The main advantage of employing natural fibers is that these are biodegradable and renewable, and exhibit low cost, low density and high toughness. However, the weak compatibility between fibers and polymer matrix, the low dispersion degree of the fibers, as well as its poor moisture resistance, generally leads to low performance materials, limiting their use. Other factors, which can largely affect the composite properties, are concerned with the size, geometry and dispersion of filler particles in the matrix. In order to improve the interfacial interactions between polymer and fibers, surface modification of the fibers and/or polymer functionalization, as well as addition of compatibilizers is required (Figure 1) [1].

Figure 1. Structure-processing-property relationships of thermoplastic composites with natural fibers.

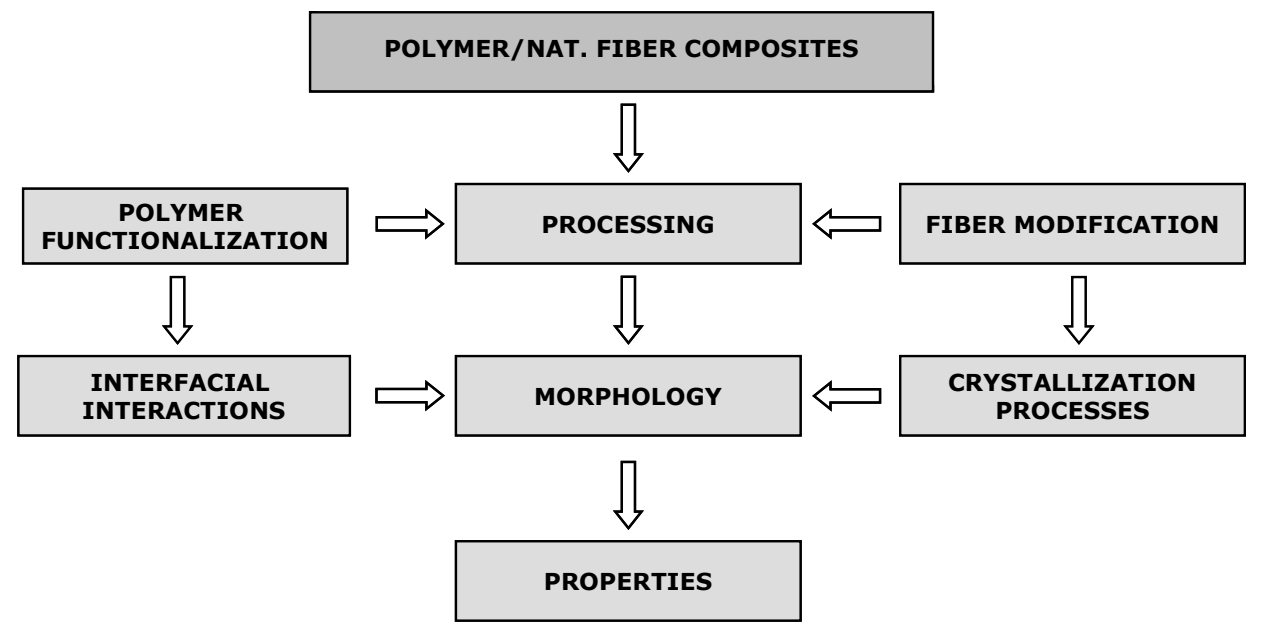

Enhanced interfacial adhesion for composites containing natural fibers can be achieved by chemical/physical treatments of the fibers or by use of specific interfacial additives [2-3]. Traditional chemical treatments of the fibers include extraction with alcohol, benzene or $\mathrm{NaOH}$ (delignification, bleaching, etc.). The other important possibility is the insertion of functional molecules which can be exploited in secondary reactions (i.e., radical grafting) with the polymer matrix, providing a stable network of bonding between the components. Effective methods of chemical modification of fibers have been developed by means of reaction with various reactive monomers, such as acetic anhydride, stearic acid [4], maleic anhydride [5,6], glycidyl methacrylate [7], silane and isocyanate [8]. Grafting of methyl methacrylate (MMA) onto sisal fibers was found to improve the surface adhesion and dispersion of the fibers in composites with PP matrix, giving rise to enhanced thermal stability and mechanical properties [9]. Similar findings were reported for PVC based composites reinforced henequen cellulose fibers grafted with MMA [10]. Rozman et al. [11] showed that compounding MA 
treated EFB (palm empty fruit bunch) with PP matrix in the melt, in the presence of peroxide, resulted in a marked change of mechanical properties due to the grafting reaction of MA double bond with PP chains.

Polymer modification with unsaturated polar molecules (such as anhydrides, epoxides, amines, etc.) is another way that has been explored to enhance interfacial adhesion, especially for polyolefin based composites [3]. Polymer modification appears to be a quick, effective method to provide good interfacial adhesion, in contrast to fiber modification, which generally involves solvent based processes. Maleated PP (PP-g-MA) have been extensively used as compatibilizers in various polyolefin composites with natural fibers [12-14]; glycidyl methacrylate grafted PP (PP-g-GMA) has been employed in composites of PP with hemp fibers [15].

We analyzed the effect of reactive compatibilization processes on the morphological, thermal and mechanical properties of thermoplastic composites, both with crystalline and amorphous matrix, based on isotactic polypropylene (PP), polystyrene (PS), poly(ethylene-vinyl acetate) (EVA) and polyesters, containing hemp, cellulose or oat as natural fillers, respectively. In the case of PS based systems, the properties of composites reinforced with $\mathrm{CaCO}_{3}$ particles were also investigated. In particular, the study was aimed at evaluating the role of various compatibilization methods, processing conditions and compatibilizer structures, as well as the type and concentration of filler, on the interfacial interaction phenomena, the crystallization processes of the polymer matrix and, finally, the degradation behavior of these materials.

\section{Experimental Section}

\subsection{Materials}

Isotactic polypropylene (PP) with MFR = $12 \mathrm{~g} / 10 \mathrm{~min}$ was purchased from Targor (Italy). Polystyrene (PS) was a (1:1) mixture of crystal type and high impact Polystyrene. Ethylene-vinyl acetate (EVA) with $28 \%$ vinyl acetate, trade name Elvax $220 \mathrm{~W}$ (density $=0.951 \mathrm{~g} / \mathrm{cm}^{3}$, $\left.\operatorname{MFR}_{\left(190^{\circ} \mathrm{C} / 2.16 \mathrm{Kg}\right)}=150 \mathrm{~g} / 10 \mathrm{~min}\right)$, was supplied by DuPont (Italy).

Hemp fibers (cannabis sativa) were supplied by Technical University of Poznan (Poland); the fibers were ground in a laboratory miller (Frish-Pulverisette 14, GmbH) up to a length less than $250 \mu \mathrm{m}$ and then treated with caustic soda to remove surface impurities (Hemp-OH). Oat particles (avena sativa) derived from ground oat husks (size $<75 \mu \mathrm{m}$ ) were supplied by Chemical Net (Poland). According to the supplier, the particles contained $50 \mathrm{wt} . \%$ cellulose, $25 \mathrm{wt} \%$ hemicellulose and 3-5 wt.\% lignin. Cellulose fibers (Technocel 75, 165 and 500-Here referred to as Cell, Cell-1 and Cell-5) having an average length of 75, 190 and $340 \mu \mathrm{m}$, respectively, and cellulose content of $99.6 \%$, were provided by Neuchem (Italy). Maleic anhydride (MA), purity min. 99.8\%, was purchased from RPE, Milan, Italy. Glycidyl methacrylate (GMA), purity 97\%, was purchased from ALDRICH, Italy.

\subsection{Chemical Modification and Compatibilizers}

Hemp and cellulose fibers were modified with GMA following the procedure reported by Rozman et al. [7]. The fibers were reacted at $90{ }^{\circ} \mathrm{C}$ with glycidyl methacrylate/triethylamine 
(3:7 vol/vol) solution. Hydroquinone was added in order to minimize the effect of free radical reaction at the unsaturated end of GMA molecules. After reaction, the modified fibers were separated by filtration and rinsed with acetone to remove the unreacted reagent and possible GMA homopolymer formed during the reaction. Modification of cellulose with MA $(0.5 \mathrm{~mol} / \mathrm{mol}$ of anhydro glucose unit $)$ was carried out into acetone suspension by refluxing the solvent at $55{ }^{\circ} \mathrm{C}$. The modified cellulose was then cooled to room temperature, separated by filtration, washed with water and acetone, then dried at $50{ }^{\circ} \mathrm{C}$ under vacuum.

PP was modified with glycidyl methacrylate (PP-g-GMA, 5 wt.\% GMA) according to a melt radical grafting procedure reported elsewhere [16] and employed as compatibilizer for PP/Hemp composites. Commercial samples of a styrene-(ethylene-butene)-styrene three-block copolymer grafted with maleic anhydride (SEBS- $g$-MA) by Shell (Kraton FG-1901X, MFR= 20-25 g/10 min) containing 1 wt.\% MA, and a poly(styrene-co-maleic anhydride) copolymer (PS-co-MA) by Sigma-Aldrich $\left(M_{w}=224.000\right.$, $\mathrm{MFR}=1.7 \mathrm{~g} / 10 \mathrm{~min}$ ) containing $7 \mathrm{wt} . \% \mathrm{MA}$, were used as compatibilizers for PS/Cell samples. Low molecular weight poly(ethylene glycol) (PEG) with $M_{w}=600$ by Sigma-Aldrich was employed in $\mathrm{PS} /$ Oat composites. Before use all materials were carefully dried under vacuum at $90{ }^{\circ} \mathrm{C}$ in order to reduce the moisture content.

\subsection{Mixing Procedures}

Composites of PP and PP-g-GMA with hemp (PP/Hemp, PP-g-GMA/Hemp, PP/PP-g-GMA/Hemp) and modified hemp (PP/Hemp-GMA) at various composition ratios were prepared in a Brabender-Plasticorder internal mixer at $170{ }^{\circ} \mathrm{C}(60 \mathrm{rpm}, 7 \mathrm{~min})$ using different compounding procedures. Composites of PS with cellulose (PS/Cell) or oat (PS/Oat) and with $\mathrm{CaCO}_{3}\left(\mathrm{PS} / \mathrm{CaCO}_{3}\right)$ were obtained by melt mixing the components in Brabender at $180 / 200{ }^{\circ} \mathrm{C}$ ( $50 \mathrm{rpm}, 8 \mathrm{~min}$ ). For these materials, the natural fillers were used as received, without any surface treatment. Compatibilized systems (PS/PS-co-MA/Cell, PS/SEBS-g-MA/Cell), with various fiber amount (10-40\%) and compatibilizer content (2-16 pph), were prepared by using single- and double-step mixing procedures. Plain polymers and their mixtures with copolymers were processed under the same conditions; the torque moment in the mixer was also-monitored as a function of the mixing time.

Blends of MaterBi-K (MBK), from Novamont (Italy) and polypropylene (PP) from Montell (Italy) were prepared in Brabender-Plasticorder mixer. Polypropylene-graft-maleic anhydride (PP-g-MA) was used as compatibilizer (0-15 wt.\%). Composites of MBK/PP blends with Hemp fibers, previously treated with $\mathrm{NaOH}$, were prepared by a two-step process. Masterbatches of MBK and Hemp (60/40 w/w) were obtained by melt mixing at $175^{\circ} \mathrm{C}$ and then diluted with various amounts of PP (and PP-g-MA). Bis-1-(tert-butylperoxy)-1-methylethyl benzene was also employed as radical initiator.

\subsection{Morphological, Thermal, Rheological and Mechanical Analyses}

The morphology of blends was examined on the surfaces of bulk samples and films, freeze-Fractured in liquid nitrogen; the samples were sputter-coated with a fine layer of gold in an Edward sputter coater and analyzed with a Jeol T300 scanning electron microscope. 
Polarized optical microscopy was also employed for the study of the crystal growth in PP/Hemp composites. The samples were examined with a Leitz Ortholux II POL optical microscope equipped with a hot stage (Linkam, THMSE 600). Films sandwiched between microscope glass slides were isothermally crystallized from the melt at various temperatures, recording the growth of spherulites as a function of crystallization time.

FT-IR spectra of films of composites and plain components, obtained by compression molding at $170 / 180{ }^{\circ} \mathrm{C}$, were recorded by means of a Perkin-Elmer spectrophotometer (mod. 2000) in the 4,000-400 $\mathrm{cm}^{-1}$ frequency range, with a resolution of $2 \mathrm{~cm}^{-1}$.

Wide-angle X-ray diffraction (WAXD) analysis of PP composites was performed at room temperature with DRON-20 diffractometer connected with a Phillips generator operating at $50 \mathrm{kV}$ and $30 \mathrm{~mA}$, using CuKa radiation $(\lambda=0.1546 \mathrm{~nm})$.

The thermal behavior of all materials was examined with a Pyris Diamond DSC (Perkin-Elmer) at a heating/cooling rate of $10{ }^{\circ} \mathrm{C} / \mathrm{min}$, under nitrogen flow. The samples $(5-10 \mathrm{mg})$ were first heated to $190{ }^{\circ} \mathrm{C}$ for $2 \mathrm{~min}$, then cooled to room temperature and again heated up to $190{ }^{\circ} \mathrm{C}$ (2nd heating run). Temperatures and heats of transition were measured at the max and from the areas of the crystallization/melting peaks. Glass transition temperatures were determined at the midpoint of the heat capacity change. For the isothermal crystallization kinetics, samples were heated up to a temperature above the melting point, kept at this temperature for $5 \mathrm{~min}$ in order to erase any previous thermal history and then rapidly cooled $\left(100{ }^{\circ} \mathrm{C} / \mathrm{min}\right)$ to a prefixed $T_{c}$, recording the heat of crystallization as a function of time. The starting time for the crystallization was taken as the time at which the sample temperature reached the programmed $T_{\mathrm{c}}$ value, and the weight fraction $X_{\mathrm{t}}$ of material crystallized after time $t$ was evaluated by the ratio of the crystallization area, at the time $t$ over the total area. The half-time of crystallization at each temperature was determined from the plots of $X_{\mathrm{t}}$ versus $t$ as the time corresponding to $X_{\mathrm{t}}=0.5$.

Thermal degradation of composites and pure components was analyzed with a TGA MK2 (Rheometric Scientific) in the range from 50 to $800{ }^{\circ} \mathrm{C}$ at a heating rate of $10{ }^{\circ} \mathrm{C} / \mathrm{min}$, both in $\mathrm{N}_{2}$ atmosphere and air.

DMTA analysis was carried out by a Gabo Qualimeter Eplexor 100N (Germany) on injection molded samples in dumbbell shape obtained by a Proma WL-5 micro-injector (Torun, Poland). Glass transition temperature, $T_{\mathrm{g}}$ and $\tan \delta$ values were calculated for all samples from DMTA analysis in the temperature range from -80 to $50{ }^{\circ} \mathrm{C}$. The tests were carried out at a frequency of $1 \mathrm{~Hz}$.

Measurements of rheological properties were performed using a MCR 301 Anton Paar with parallel-plate geometry rheometer. Tests were carried out in steady rate mode at $180{ }^{\circ} \mathrm{C}$ (molten state). Tests were done in a range of rates from 0.1 to $500 \mathrm{~s}^{-1}$. For all experiments, the strain amplitude was maintained constant at $2 \%$.

Mechanical analysis was carried out by means of an Instron testing machine. Sheets of $1 \mathrm{~mm}$ and $0.4 \mathrm{~mm}$ thickness were obtained for PP and PS composites, respectively, by compression molding in a Carver laboratory press at $170 / 190{ }^{\circ} \mathrm{C}$ for $5 \mathrm{~min}$, followed by slow cooling at room temperature. Test specimens were cut from the sheets in a bar shape with length of $50 \mathrm{~mm}$ and width of $10 \mathrm{~mm}$. Tensile tests were carried out at room temperature on at least 5 specimens of each sample, using cross-head speeds of $0.5 \mathrm{~mm} / \mathrm{min}$ for PP composites and $5 \mathrm{~mm} / \mathrm{min}$ for PS composites. 


\section{Results}

\subsection{PP/Hemp Composites}

Modification of hemp fibers was performed by exploiting the reaction of the hydroxyl groups of hemp (after treatment with $\mathrm{NaOH}$ ) with GMA monomer in triethylamine solution, which gives rise to the formation of ether bonds on the fiber surface (Hemp-GMA), according to the procedure described in [15]. The Hemp-GMA fibers could react with PP during the melt mixing, in the presence of a radical initiator (BTP), through the attack of PP macroradicals on the double bond of methacrylate moiety of GMA [Figure 2(a)].

Figure 2. Scheme of (a) hemp modification with GMA and grafting onto PP, (b) grafting of GMA onto PP and reaction with hemp.

(a)
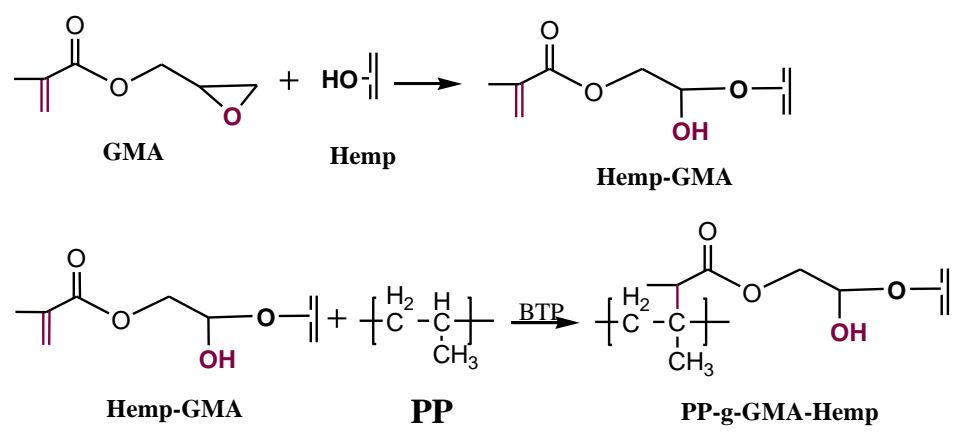

(b)
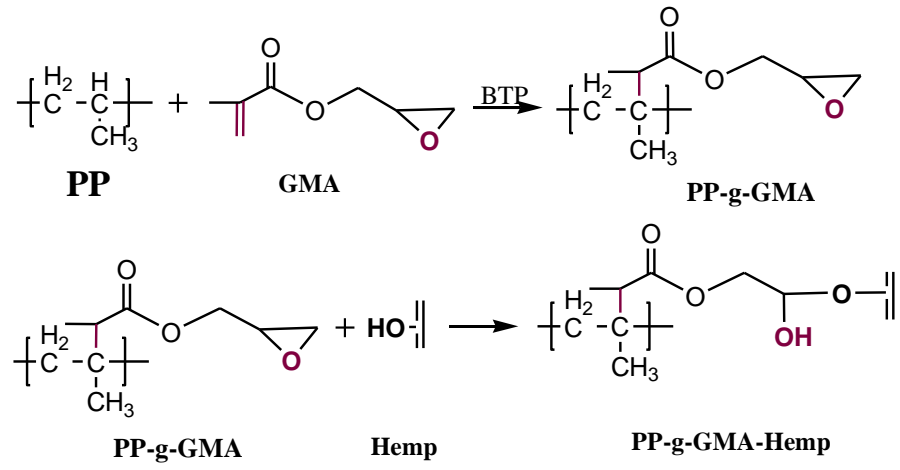

PP functionalization was obtained by melt grafting of GMA in the presence of BTP radical initiator [16]; then PP-g-GMA reacted with hemp during melt mixing by exploiting the reaction of the epoxide ring of GMA with the $\mathrm{OH}$ groups of fibers [Figure 2(b)].

The grafting reactions were monitored by means of FT-IR spectroscopy: Spectra of modified fibers, recorded at different reaction times, showed a marked absorption in the carbonyl region $\left(1,710 \mathrm{~cm}^{-1}\right)$ and peaks $\left(1,668\right.$ and $\left.1,630 \mathrm{~cm}^{-1}\right)$ associated with the methacrylic ester bond and the double bond of GMA, respectively. The SEM analysis of PP/Hemp-GMA and PP/Hemp/PP-g-GMA composites clearly indicated an improved adhesion of the fibers to the matrix as a consequence of the effective interactions at the interface (Figure 3).

The effect of fibers modification and concentration on the phase behavior of polymer matrix was examined by DSC under dynamic and isothermal conditions. The addition of hemp to PP resulted in an 
increase of crystallization temperature and crystallinity of PP matrix, and a further increase was observed in the presence of modified fibers (PP/Hemp-GMA).

Figure 3. SEM micrographs of (a) PP/Hemp 90/10 and (b) PP/Hemp 90/10 compatibilized with PP-g-GMA (10 pph).
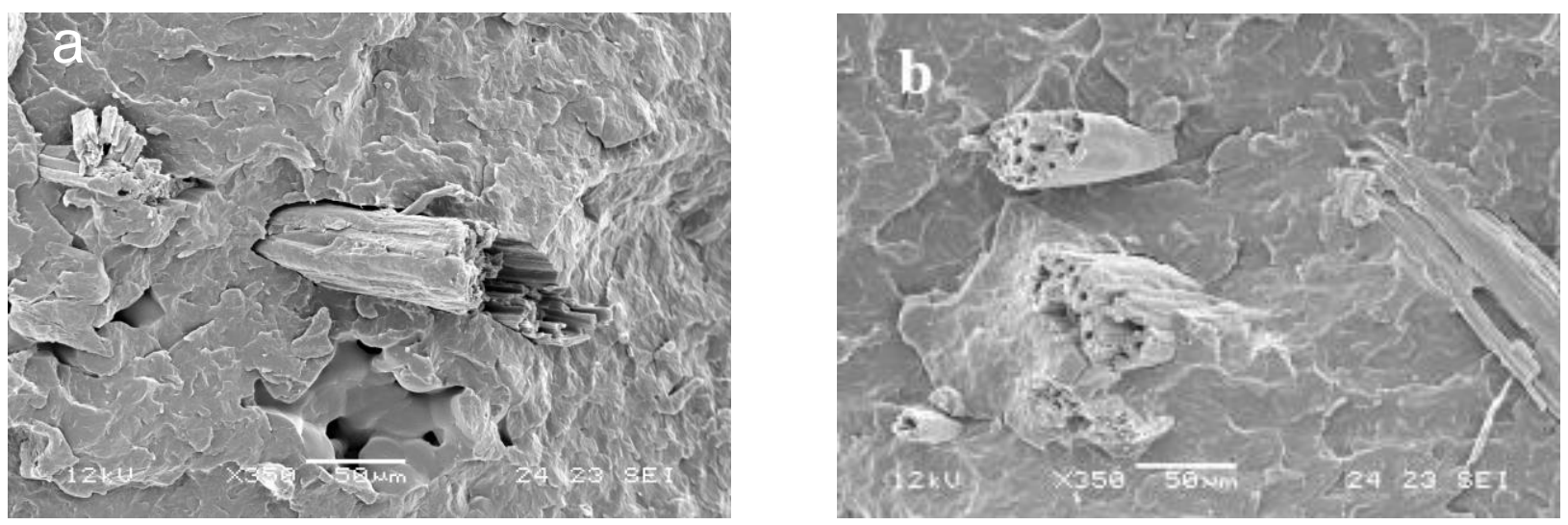

The crystallization behavior of the matrix was examined by studying the isothermal crystallization kinetics of the various samples in the range $120-138^{\circ} \mathrm{C}$ using the Avrami model [17]:

$$
X_{t}=1-\exp \left[-K_{n} \mathrm{t}^{n}\right]
$$

where $K_{n}$ is the kinetic constant and $n$ the Avrami exponent, depending on growth geometry and nucleation type of the crystals.

The variation of the crystallization half-time $\left(t_{0.5}\right)$, i.e., the reciprocal of the overall crystallization rate, is pointed out in Figure 4 for all examined samples, as a function of the crystallization temperature, $T_{\mathrm{c}}$. An increase of about one order of magnitude in the crystallization rate of composites with respect to neat $\mathrm{PP}$, at the same $T_{\mathrm{c}}$, was noticed for the whole temperature range. In particular, the composites with modified Hemp (PP/Hemp-GMA 90/10 and 80/20) displayed higher crystallization rates (lower $t_{0.5}$ ) than PP/Hemp. Moreover, as shown in Figure 5, the observed values of the Avrami exponent $n$ indicated that the nucleation process of the polymer crystals was affected by the fibers. Since the overall crystallization rate of the polyolefin is related to the spherulite growth rate, and the number of primary nuclei per unit volume [18], and as the growth rate is not affected by the fiber content, the increase of the overall crystallization rate in the composites can be ascribed to the increased crystal nucleation density on the fiber surface [19,20]. This effect was more marked for composites with Hemp-GMA mainly as a consequence of the enhanced fiber-matrix interactions.

The DSC analysis of the melting behavior of isothermally crystallized samples showed a double melting peak for PP/Hemp-GMA composites and a single melting peak for PP and PP/Hemp samples (Figure 6). According to the polymer crystallization theory [21], plots of the melting temperature, $T_{\mathrm{m}}$, as a function of $T_{\mathrm{c}}$, displayed an increasing linear trend for all examined samples. Extrapolation of the lines to $T_{\mathrm{m}}=T_{\mathrm{c}}$ gives values of equilibrium melting temperature $\left(T_{\mathrm{m}}^{\circ}\right)$ near to $190{ }^{\circ} \mathrm{C}$ for PP [18] and PP/Hemp, and about $176{ }^{\circ} \mathrm{C}$ for PP/Hemp-GMA. The decrease of $T^{\circ}$ m recorded for the samples with modified fibers, suggests that the thermodynamic stability of the PP crystals is decreased mostly owing to the chemical constraints occurring at the fiber-matrix interface, as a consequence of PP grafting onto the fibers. 
Figure 4. Temperature dependence of the crystallization half-time for PP, PP/Hemp and PP/Hemp-GMA composites isothermally crystallized from the melt.

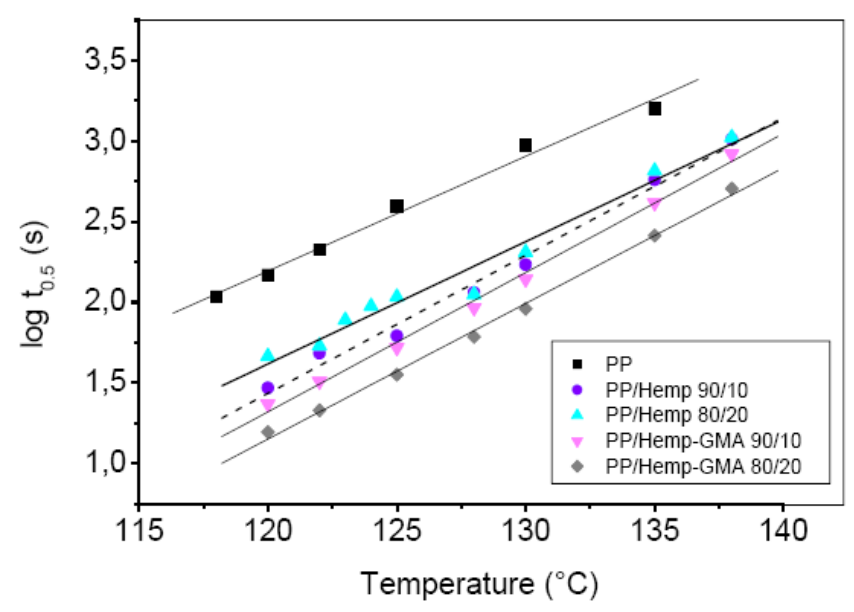

Figure 5. Values of the Avrami exponent $n$ for PP/Hemp composites isothermally crystallized from melt at various temperatures.

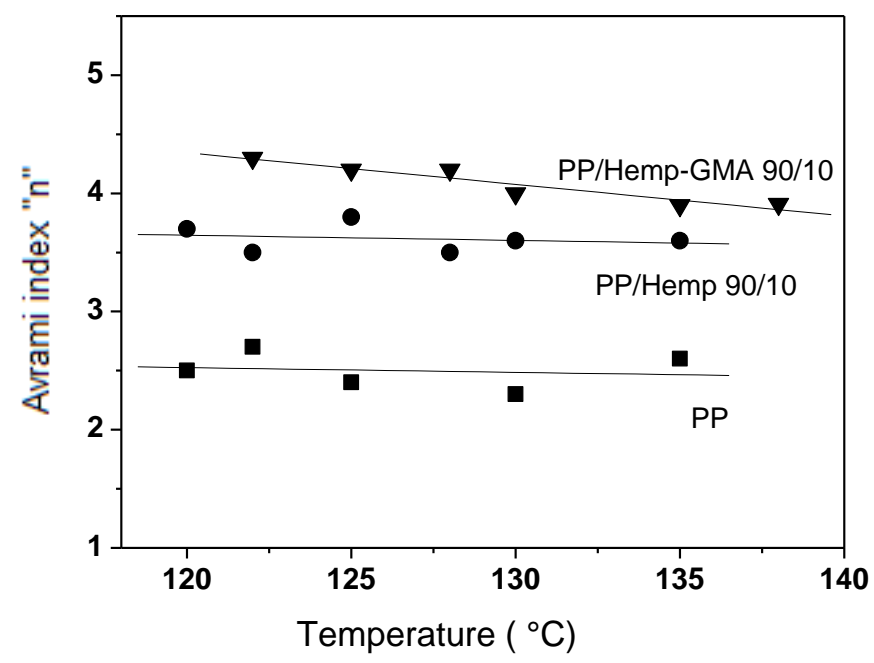

By relating the temperature dependence of the kinetic constant, $K_{\mathrm{n}}$ (Equation 1), to the activation energy for the formation of critical nuclei [21], it was possible to evaluate a change of the free energy of folding of polymer crystals, $\sigma_{\mathrm{e}}$, from $96 \mathrm{erg} / \mathrm{cm}^{2}$ for plain $\mathrm{PP}$ to about $50 \mathrm{erg} / \mathrm{cm}^{2}$ for PP/Hemp-GMA.

The results of TGA analysis evidenced a higher thermal stability of the GMA modified fibers with a maximum degradation rate at $321{ }^{\circ} \mathrm{C}$, as compared to the unmodified ones (max at about $300{ }^{\circ} \mathrm{C}$ ) and $\mathrm{NaOH}$ treated hemp ( $\max$ at about $315^{\circ} \mathrm{C}$ ) [15]. In the DTG curves of composites (Figure 7) the maximum degradation rate always shifted to a higher temperature with respect to neat PP $\left(T_{\max }=400{ }^{\circ} \mathrm{C}\right.$ ) and cellulose, the largest increase being observed for the unmodified PP/Hemp $\left(T_{\max }=462{ }^{\circ} \mathrm{C}\right)$. For composites with Hemp-GMA a lower decomposition temperature was observed $\left(T_{\max }=447^{\circ} \mathrm{C}\right)$. 
Figure 6. DSC melting curves of PP/Hemp and PP/Hemp-GMA composites isothermally crystallized from the melt at various $T_{\mathrm{c}}$ (heating rate: $10{ }^{\circ} \mathrm{C} / \mathrm{min}$ ).

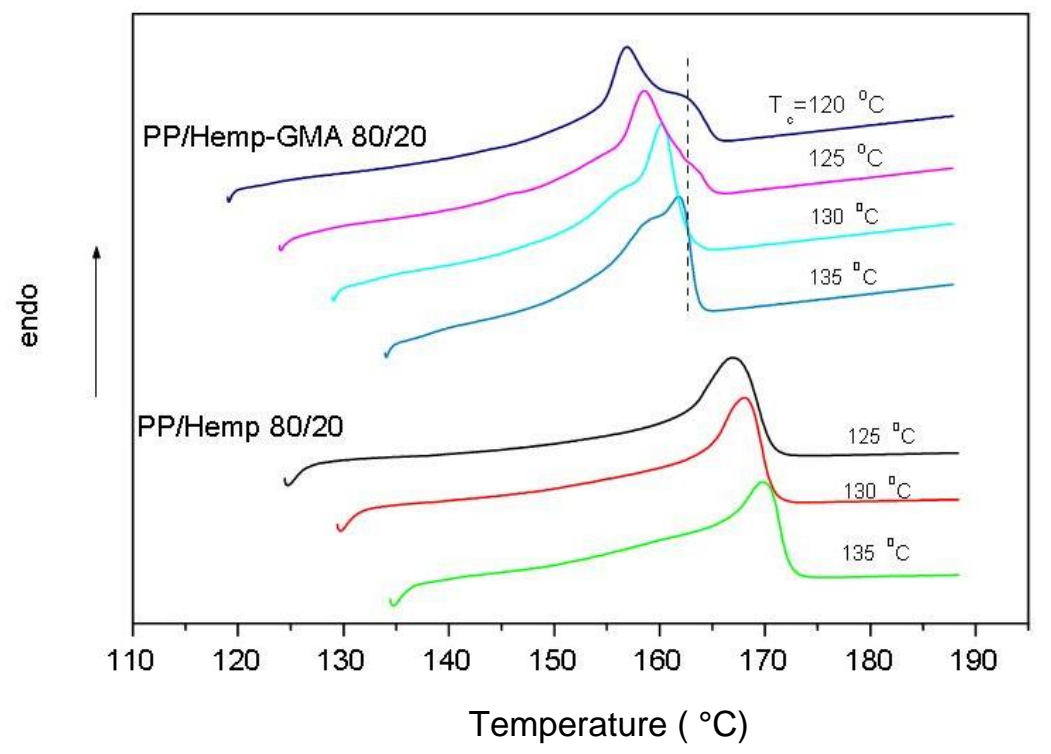

Figure 7. DTG curves of PP/Hemp and PP/PP-g-MA/Hemp composites (in $\mathrm{N}_{2}$ ).

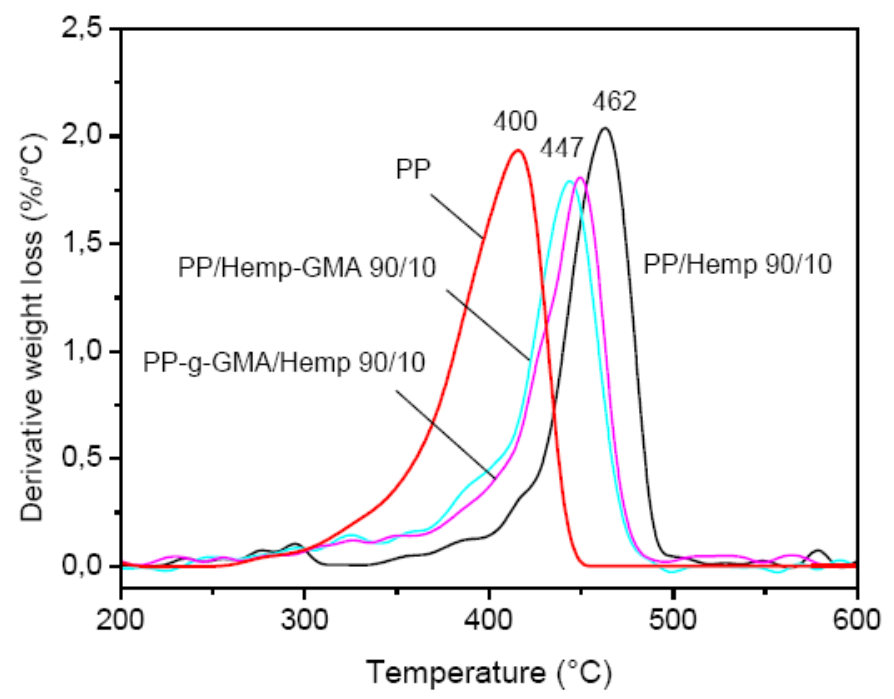

For all composites the tensile tests showed a rather brittle behavior, other than that observed for plain PP. As reported in Table 1, a marked increase of the Young modulus was found for PP/Hemp samples when compared to plain PP, while the strength at max and elongation at break decreased, as found for other natural fiber reinforced polymer composites [22-24]. An increase of stiffness was observed in the presence of PP-g-GMA, which can be related to the effect of the compatibilizer on the interfacial adhesion: Values of modulus above 3,000 MPa were found for PP/Hemp samples added with 10 pph PP-g-GMA. 
Table 1. Tensile properties of PP, PP/Hemp and PP/Hemp/PP-g-GMA composites.

\begin{tabular}{|c|c|c|c|c|c|c|}
\hline Sample & $\begin{array}{c}\text { Composition } \\
\text { crystallization }\end{array}$ & $\begin{array}{c}\text { PP-g-GMA } \\
\text { (pph) }\end{array}$ & $\begin{array}{c}\text { Tensile } \\
\text { modulus } \\
\text { (MPa) }\end{array}$ & $\begin{array}{c}\text { Stress at } \\
\text { max } \\
(\mathbf{M P a})\end{array}$ & $\begin{array}{c}\text { Stress at } \\
\text { break } \\
(\mathbf{M P a})\end{array}$ & $\begin{array}{c}\text { Elongation at } \\
\text { break } \\
(\boldsymbol{\%})\end{array}$ \\
\hline PP & 100 & - & 1800 & 31.8 & 19.8 & 18.0 \\
\hline PP/Hemp & $90 / 10$ & - & 2600 & 27.0 & 25.4 & 4.0 \\
\hline PP/Hemp & $90 / 10$ & 5 & 1900 & 27.9 & 27.2 & 3.5 \\
\hline PP/Hemp & $90 / 10$ & 10 & 3100 & 27.8 & 26.9 & 2.6 \\
\hline PP/Hemp & $80 / 20$ & - & 2800 & 25.7 & 24.8 & 2.8 \\
\hline PP/Hemp & $80 / 20$ & 5 & 2500 & 23.1 & 22.2 & 2.2 \\
\hline PP/Hemp & $80 / 20$ & 10 & 3000 & 25.7 & 25.3 & 2.3 \\
\hline
\end{tabular}

\subsection{Composites with PS Matrix}

We investigated the compatibilization and the properties of PS composites containing cellulose or oat as natural fillers. In particular, the study was aimed at evaluating the role of addition of PS copolymers containing reactive functional groups-namely PS-co-MA and SEBS-g-MA copolymers - on the interfacial interaction phenomena which control the phase structure, phase transitions and mechanical behavior of the composites [25].

SEM analysis of fracture surfaces of PS/Cell and PS/Oat composites revealed a poor adhesion between matrix and particles in all cases (Figure 8). The addition of reactive compatibilizers to PS/Cell composites determined a marked change of the morphology with improved interfacial adhesion and reduced pull-out phenomena. SEM micrographs of binary and ternary systems containing reactive copolymers (Figure 9) indicated a high adhesion between the components with quite a diffused polymer-fiber interface, which is ascribed to the occurrence of chemical interactions between MA and the hydroxyl groups on the fiber surface.

For PS/Oat and PS/CaCO 3 composites, the addition of PEG and SEBS-g-MA, respectively, caused an improvement of filler dispersion and interfacial interactions [25].

Figure 8. SEM micrographs of (a) PS/Cell and (b) PS/Oat composites.
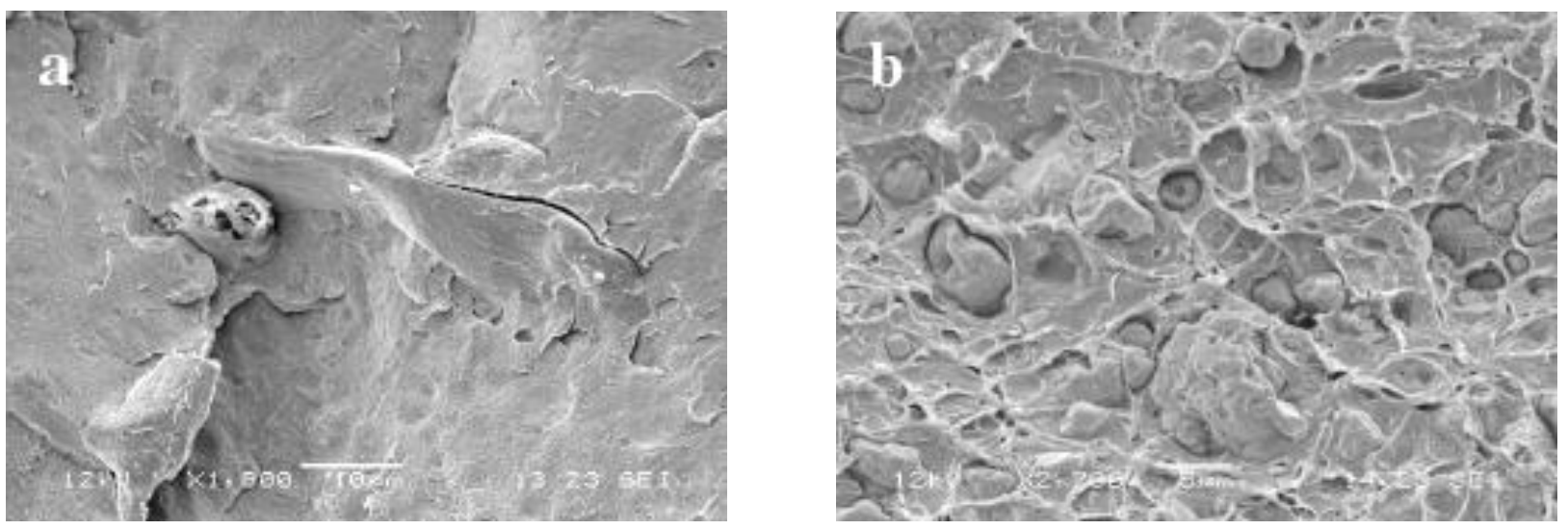
Figure 9. SEM micrographs of (a) SEBS-g-MA/Cell 50/50, (b) PS-co-MA/Cell 50/50, (c) PS/Oat/PEG composites and (d) $\mathrm{PS} / \mathrm{CaCO}_{3} / \mathrm{SEBS}-\mathrm{g}-\mathrm{MA}$.
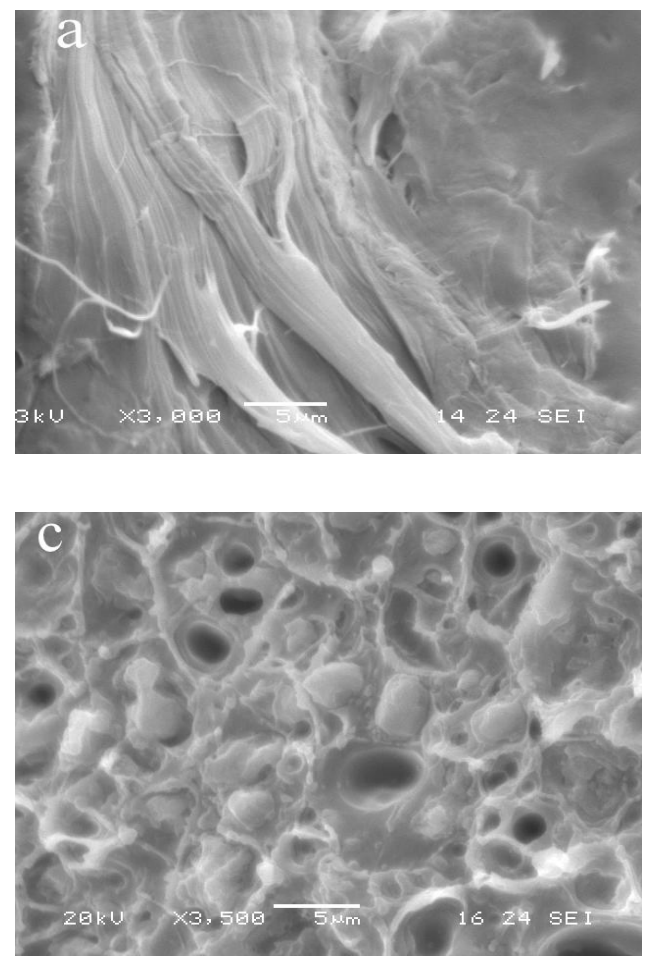
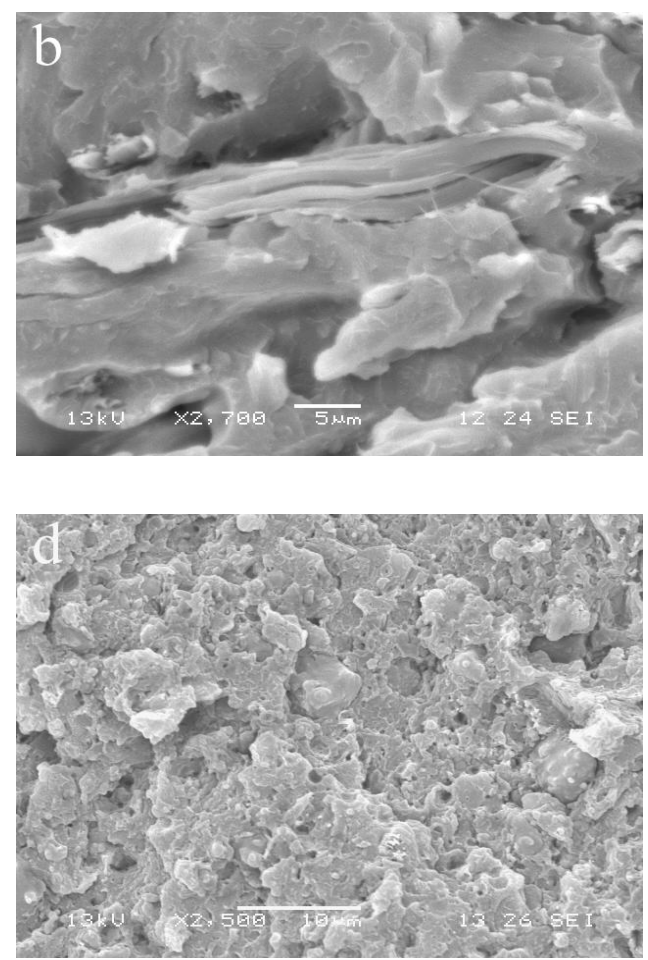

PS/Cell samples containing SEBS- $g$-MA and PS-co-MA copolymers were analyzed by FT-IR spectroscopy to investigate the effect of the compatibilizer at the polymer-fiber interface. The occurrence of interactions between maleic anhydride and hydroxyl groups of cellulose was carefully examined in the frequency ranges $2,000-1,650 \mathrm{~cm}^{-1}$ and $1,200-850 \mathrm{~cm}^{-1}$ respectively. The reaction scheme and FT-IR spectra of composites are shown in Figure $\mathbf{1 0}$ and $\mathbf{1 1}$ respectively. Significant shifts of the MA carbonyl stretching band ( $\mathrm{vCO}$ ) at about $1,780 \mathrm{~cm}^{-1}$ and relevant ester band ( $\mathrm{VCOO}$ ) near to $1,740 \mathrm{~cm}^{-1}$ were recorded, as well as the changes of alcohol ( $\mathrm{vCOH}$ ) and ether ( $\mathrm{vCOC}$ ) stretching in the spectra of cellulose at $1,164,1,114,1,060$ and $1,033 \mathrm{~cm}^{-1}$ respectively; supporting the formation of stable ester bond at the fiber/matrix interface [26,27].

Figure 10. Reaction scheme of SEBS-g-MA and Cellulose.

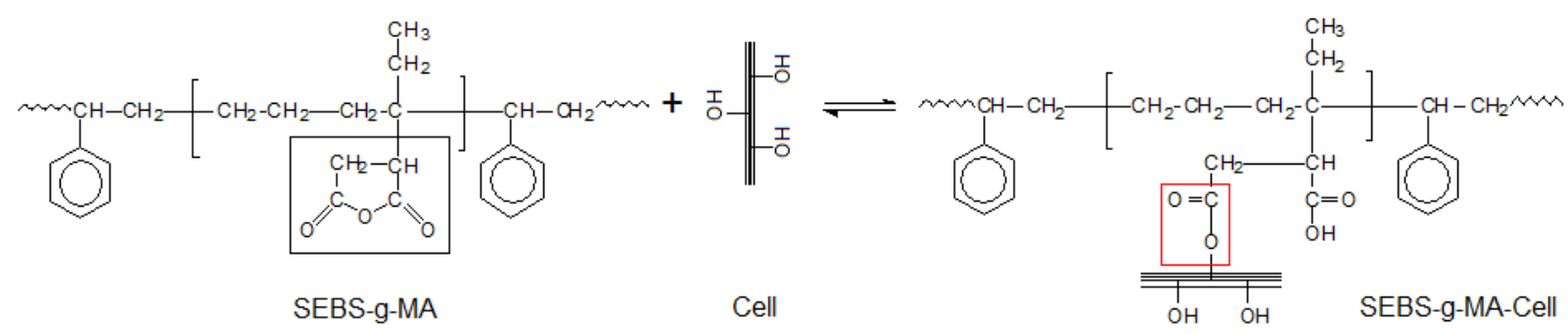


Figure 11. FT-IR spectra of PS/Cell compatibilized with SEBS- $g$-MA and PS-co-MA, in the region $800-1,200 \mathrm{~cm}^{-1}$ (compatibilizer amount in $\mathrm{pph}$ ).
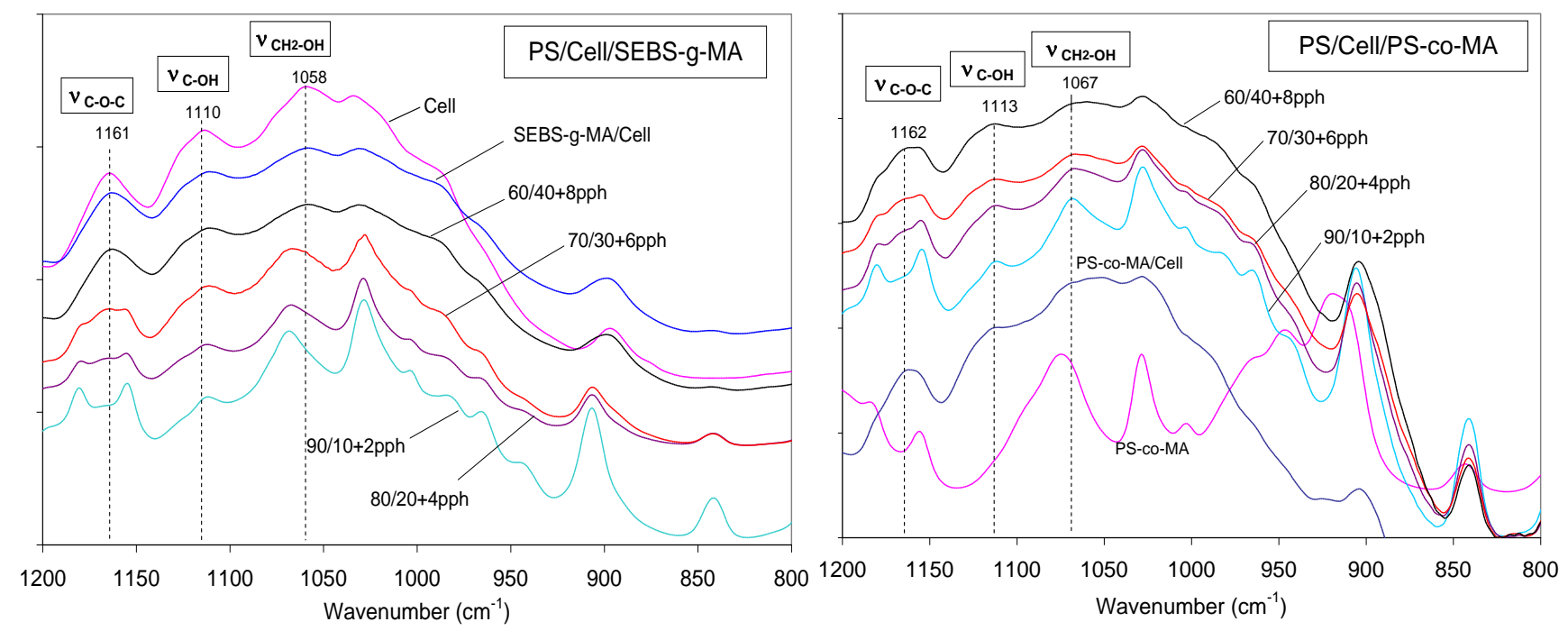

The glass transition behavior of the PS matrix in the composites was examined by DSC as a function of the filler content and type of compatibilizer. For uncompatibilized PS/Cell samples, a variation of $T_{g}$ was observed only at higher contents of cellulose, while a significant effect was recorded on the addition of compatibilizer. For samples containing SEBS- $g$-MA, $T_{g}$ increased on increasing the fiber content from $94{ }^{\circ} \mathrm{C}$ (plain PS) to about $100{ }^{\circ} \mathrm{C}(40 \%$ by weight of Cell), but a minor increment was found for samples compatibilized with PS-co-MA.

The values of tensile modulus, for binary composites of PS with Cell, Oat and $\mathrm{CaCO}_{3}$, are compared in Figure 12 for filler contents ranging from 10 to 40 wt.\%. PS/Cell and PS/Oat samples showed a rather brittle behaviour similar to that observed for PP/Hemp. The variation of tensile modulus and elongation at break for PS/Cell composites, compatibilized both with PS-co-MA and SEBS- $g$-MA, is reported in Figures 13 and 14 respectively, as a function of fiber content.

Figure 12. Values of elastic modulus for PS/Cell, PS/Oat and $\mathrm{PS} / \mathrm{CaCO}_{3}$ composites vs. filler content.

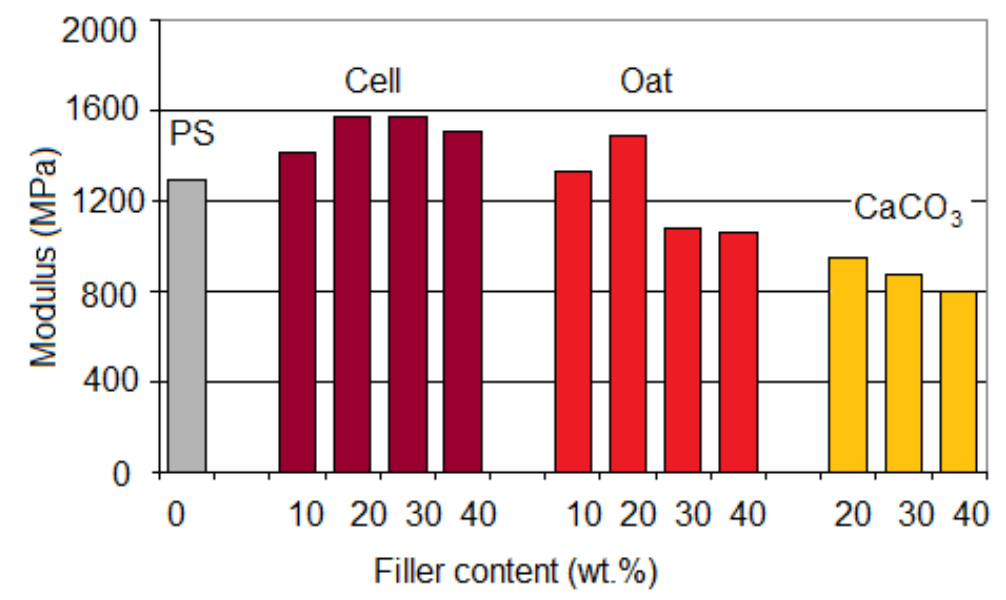


Figure 13. Elastic modulus of PS/Cell composites compatibilized with PS-co-MA and SEBS- $g$-MA (at different copolymer/fiber ratios) as a function of cellulose content.

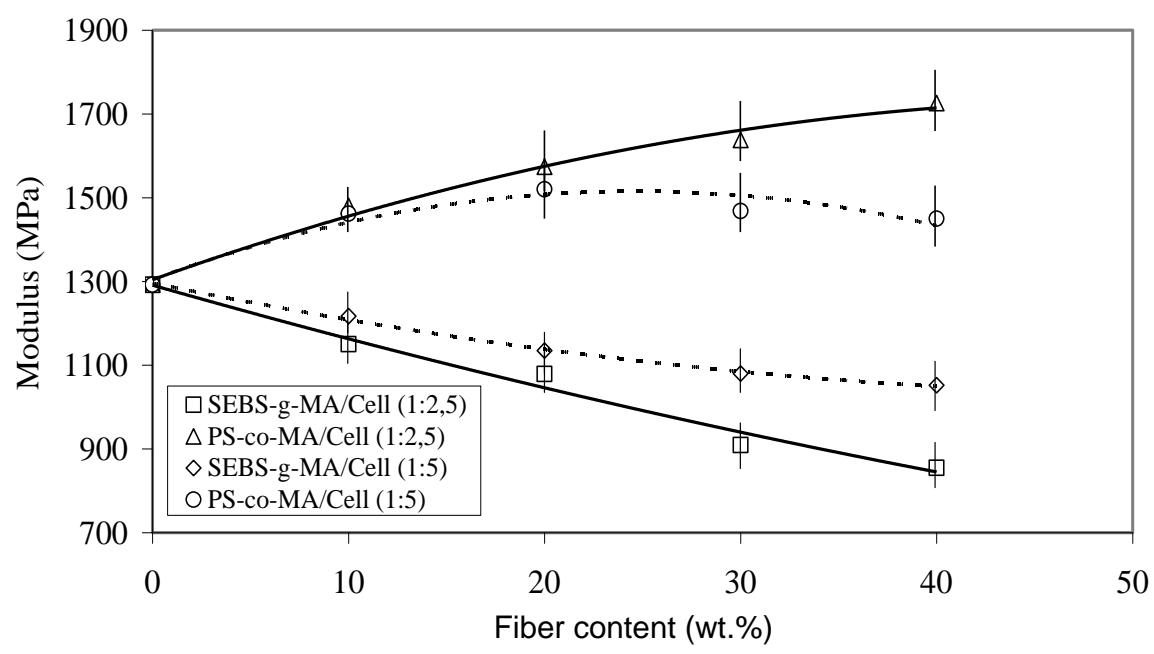

A marked increase of the modulu,s up to about 1,750 MPa, was found for PS/Cell (60/40) upon addition of PS-co-MA (16 pph), while the strength at max and elongation at break decreased, depending on the fiber/compatibilizer ratio (Figure 14). Otherwise, the addition of SEBS-g-MA copolymer caused a ductile behavior with lower modulus and increased elongation at break, owing to the ethylene-butene elastomeric block in the copolymer chain [28]. However, as it was pointed out by SEM analysis of fracture surfaces of binary SEBS-g-MA/Cell samples, a stronger surface adhesion accompanied by extended fiber fraying was noticed with respect to PS-co-MA/Cell samples. For PS/Oat composites the addition of PEG (5-10 pph), as plasticizer, resulted in a decrease of modulus and tensile strength, but with a steady improvement of the elongation at break.

Figure 14. Effect of cellulose content on the elongation at break of PS/Cell composites containing PS-co-MA and SEBS- $g$-MA (at different copolymer/fiber ratios).

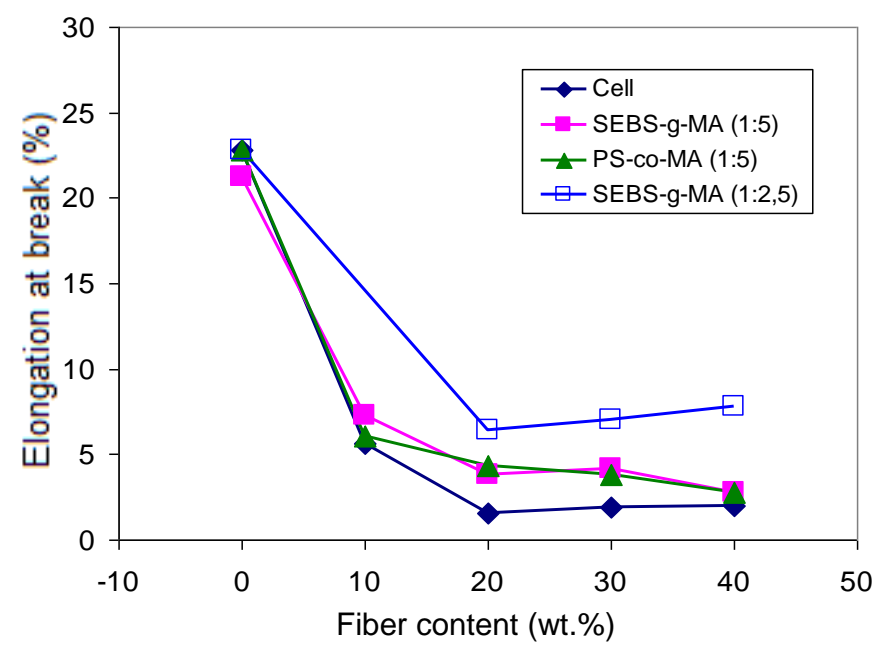




\subsection{Composites with EVA Matrix}

Ethylene vinyl acetate (EVA) copolymers, due to their important rubber and resin properties [29], are used for several applications, such as packaging films, adhesives coatings, cable insulation, barrier sheets, etc. [30]. However, the properties of EVA composites have been analyzed for a limited number of systems. It has been reported that wood powder (WP) influenced the crystallization behavior of EVA for composites of PP/EVA blends with WP [31]. For composites of EVA and cellulose acetate (CA) containing natural fibers (Sterculia villosa), it was found that the tensile strength of EVA composites decreased with the addition of fiber; whereas in CA composites, tensile strength increased due to the well distribution of fibers [32]. EVA/Sisal fiber composites were prepared by melt mixing in the presence of dicumyl peroxide (DCP) as radical initiator, and it was found that grafting between EVA and Sisal fiber took place. These composites were thermally more stable than both EVA and Sisal fiber alone [33]. For PP/EVA/Cell composites, it has been reported that EVA improved the resistance of the composites to water absorption [34].

We examined the structure-property relationships of EVA composites with cellulose fibers modified with maleic anhydride and glycidyl methacrylate for improving the interfacial adhesion and thus the compatibility between the components. We focused attention on the effect of functional groups on the cellulose surface on the morphology, thermal behavior, mechanical properties and fiber-matrix interactions of these systems.

The functionalized cellulose fibers were characterized by SEM and FT-IR analysis. The fiber surfaces displayed extended roughness after modification, in contrast with the smooth surface of the untreated cellulose. The FT-IR spectra of MA treated cellulose displayed an extra peak at $1,570 \mathrm{~cm}^{-1}$ corresponding to $-\mathrm{COOH}$ group, due to the chemical reaction between the hydroxyl groups of cellulose and maleic anhydride [35]. In the spectrum of GMA treated cellulose an intense carbonyl stretching peak was observed at $1,718 \mathrm{~cm}^{-1}$, supporting the reaction between epoxy groups of GMA and $\mathrm{OH}$ groups of cellulose. The degree of substitution of GMA treated cellulose (DS $=0.16$ ) was also examined by elemental analysis. The variation of torque moment recorded during melt mixing in Brabender indicated that the reaction between cellulose and EVA polymer took place.

SEM micrographs of the fracture surfaces of EVA/Cell-GMA and EVA-GMA/Cell composites are presented in Figure 15. Samples of unmodified EVA/Cell show poor adhesion between fiber and polymer with frequent pullout phenomena of the fibers. Otherwise, the fracture surfaces of samples with functionalized components display good interfacial adhesion and the fiber surfaces are coated with a layer of polymer. This indicates an improved compatibility of treated cellulose with EVA copolymers.

Accordingly, FT-IR spectra of EVA, Cell-GMA and EVA/Cell-GMA samples (after removing the EVA matrix with toluene) supported the presence of chemical interactions between EVA and Cell-GMA in the composites. 
Figure 15. SEM micrographs of (a) EVA/Cell-GMA 80/20 and (b) EVA-GMA/Cell 70/30.
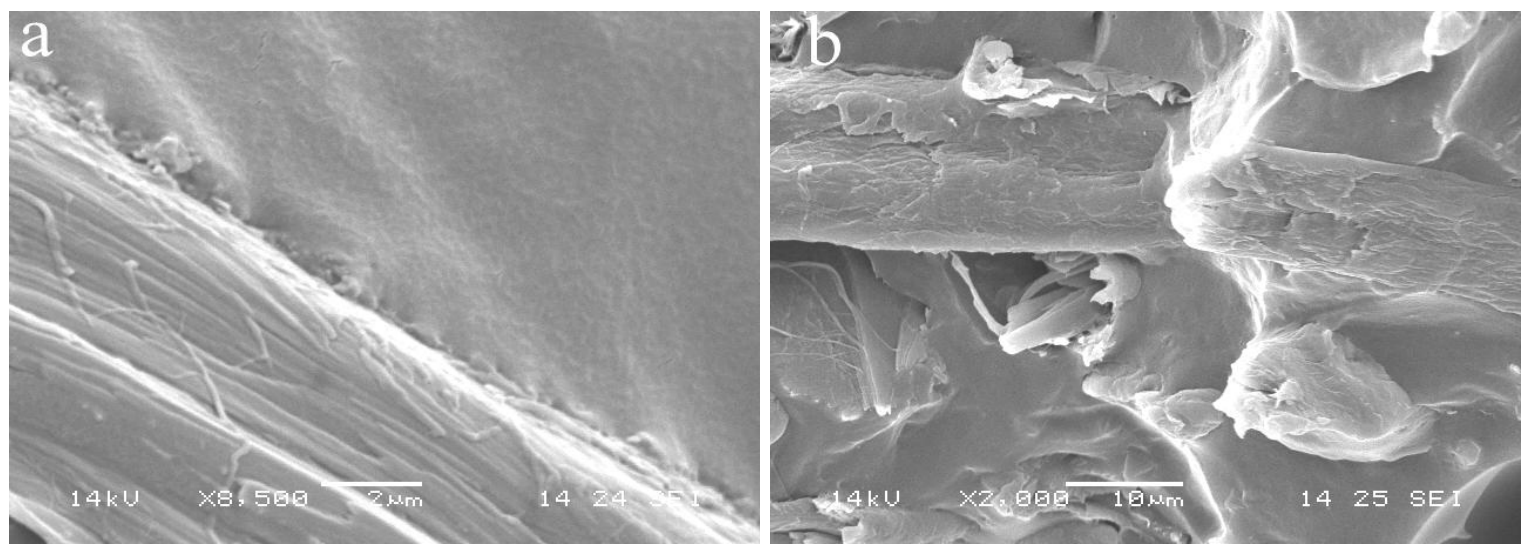

Figure 16 shows the effect of temperature on $\tan \delta$ of polymer matrices and their composites. Cellulose incorporation reduces the $\tan \delta$ peak height by restricting the movement of the polymer molecules. It was seen that cellulose fiber decreased the $T_{\mathrm{g}}$ of EVA-GMA; on the other hand $T_{\mathrm{g}}$ of EVA-MA is increased by the incorporation of cellulose. Elevation of $T_{\mathrm{g}}$ is taken as a measure of the interfacial interaction. The width of the $\tan \delta$ peak also becomes broader than that of the matrix. This behavior suggests that there are molecular relaxations in the composites that are not present in the pure matrix. Hence the width of the $\tan \delta$ peak is indicative of the increased volume of the interface [36].

Figure 16. Temperature dependence of $\tan \delta$ values for EVA-GMA, EVA-MA and composites with cellulose.

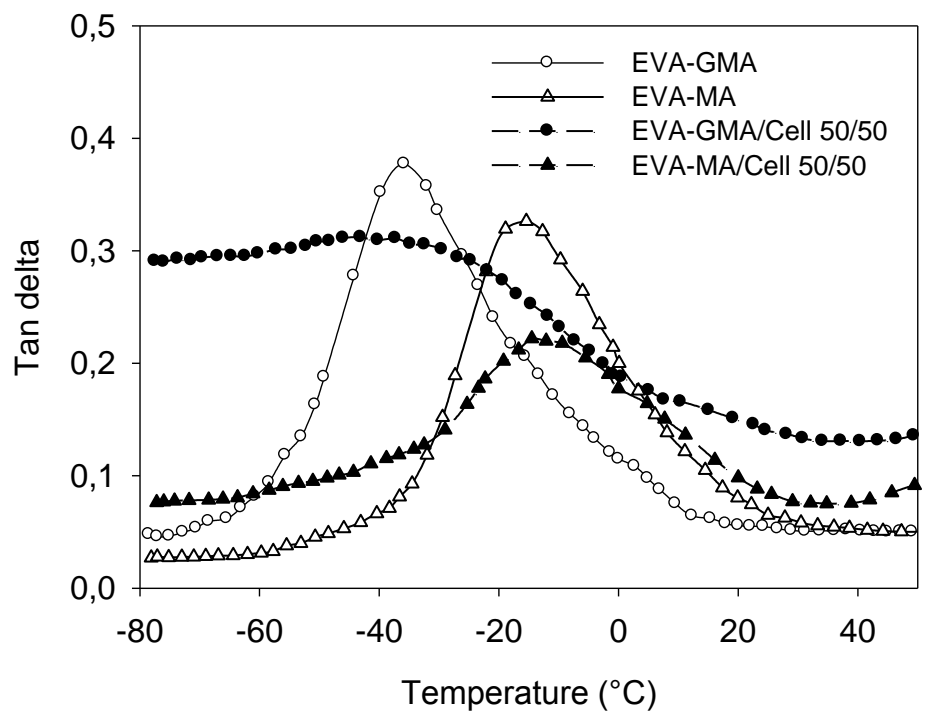

Tensile mechanical properties of polymers and corresponding composites were investigated as a function of fiber length and content. Figure 17 shows the bar chart of elastic modulus of polymer and composites with $30 \mathrm{wt} \%$ cellulose. Incorporation of cellulose to EVA, EVA-MA and EVA-GMA caused a significant increase of the elastic modulus of the composites compared to plain EVA, due to the higher modulus of cellulose, as observed for other similar systems [15,25]. Elongation at break was really reduced in all composites. It was noticed that the failure strength of EVA-GMA/Cell increased 
compared to EVA/Cell and EVA-MA/Cell. Further, higher values of elongation at break were observed for EVA-GMA composites with respect to EVA-MA based systems.

Figure 17. Effect of polymer functional groups on the Young modulus of EVA/Cell composites.

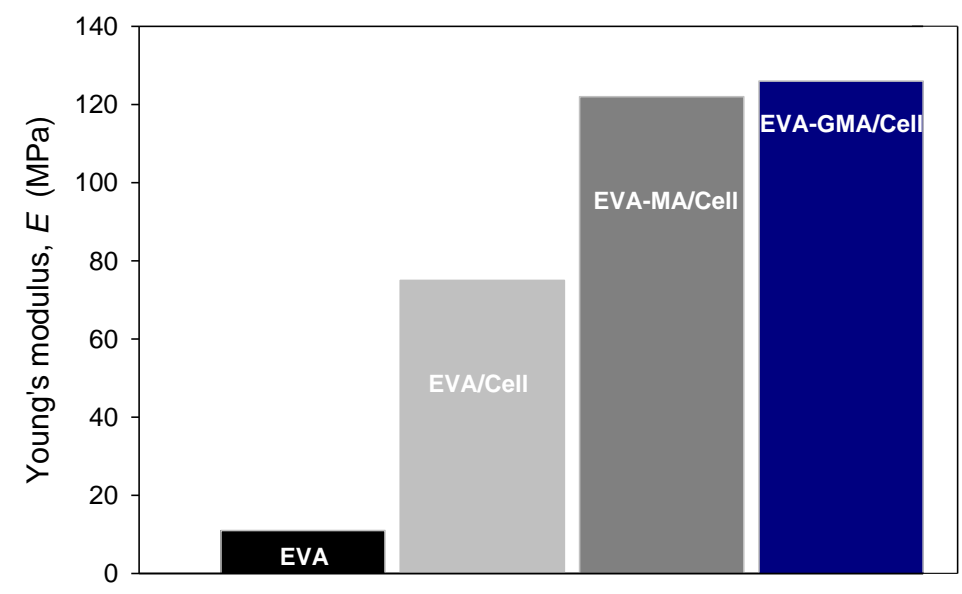

Pure EVA together with EVA-GMA exhibited a clear pseudoplastic behavior (Figure 18). On the other hand, EVA-GMA/Cell-1 and EVA-GMA/Cell-5 showed a pseudo-solid-like behavior with a pronounced shear thinning parameter. In these cases, Newtonian behavior disappeared at low frequency, suggesting a transition from liquid-like to solid-like viscoelastic behavior. Rheological behavior of neat EVA and EVA-GMA exhibits a Newtonian region at low frequency $\left(<0.1 \mathrm{~s}^{-1}\right)$ and a shear thinning region at high frequency $\left(>1 \mathrm{~s}^{-1}\right)$. It is clear that cellulose fibers have a dramatic effect on the rheological behavior: As $30 \%$ of fibers are added into the polymer matrix, the Newtonian region of the composites disappears and only the shear thinning region remains in the frequency range of 0.01 to $100 \mathrm{~s}^{-1}$.

Figure 18. Melt viscosity of EVA-GMA/Cell composites and plain polymers as a function of frequency.

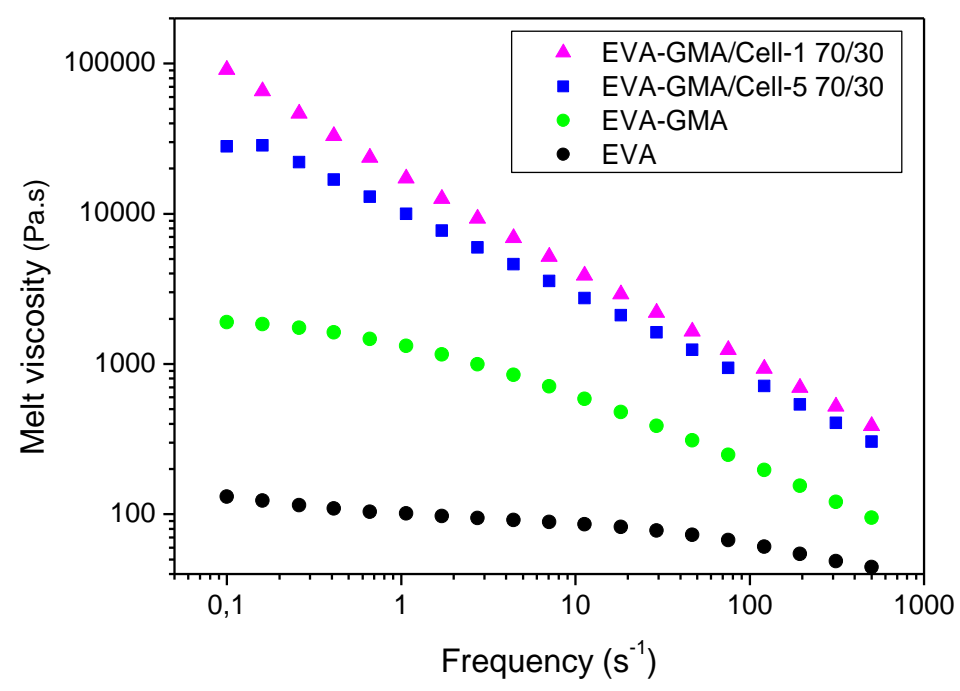




\subsection{Polyester/Polyolefin/Hemp Ternary Composites}

The combination of polyester and polyolefin offers the opportunity of joining the main physico-chemical and mechanical characteristics of different classes of polymer materials: The expected advantages are related to a reduced cost of raw materials, lower environmental impact, and new recycling opportunities.

MaterBi-K (MBK) was selected as biodegradable polymer, PP as polyolefin component and hemp as natural filler. In order to improve the matrix/fiber and MBK/PP compatibility, alkaline treatment of fibers was carried out and a maleated PP (PP-g-MA) was employed as compatibilizer. The thermal, mechanical and rheological properties of both ternary MBK/PP/Hemp (and MBK/PP/PP-g-MA/Hemp) composites, and MBK/PP (and MBK/PP/PP-g-MA) blends, were then investigated. In parallel, binary $\mathrm{MBK} /$ hemp composites were prepared and examined [37].

Blends of MBK and PP displayed poor mechanical properties owing to the incompatibility of both materials. On addition to PP-g-MA, tensile strength increased until reaching a maximum (10 wt.\%) due to the compatibilizing effect, as also indicated by SEM analysis. On the other hand, the tensile modulus was generally higher for blends and increased for lower content of PP-g-MA, then decreased due to the lower rigidity of added PP-g-MA, as compared to pure PP. The tensile strength of blends decreased when PP was incorporated to MBK.

As shown in Table 2, in the case of ternary composites, the tensile strength, $\sigma$, increased with the addition of $\mathrm{PP}$ and fibers incorporation. The modulus, $E$, remained almost constant for all studied composites, being twice that of corresponding MBK/PP/PP-g-MA blends. SEM analysis revealed a good adhesion between fibers and matrix, which in turn contributed to the enhanced mechanical properties. DSC analysis indicated that PP and fibers had little effect on the thermal behavior of MBK, whereas in the presence of PP-g-MA either in blends or composites, a marked change of crystallization and melting temperature of PP was found. This can be ascribed to the chemical interactions occurring between hydroxyl groups of natural components and MA groups.

Table 2. Mechanical and thermal properties of MBK/PP/PP-g-MA/Hemp composites.

\begin{tabular}{|l|c|c|c|c|}
\hline Matrix composition & $\boldsymbol{\sigma}(\mathbf{M P a})$ & $\boldsymbol{E}(\mathbf{M P a})$ & $\boldsymbol{T}_{\mathrm{m}}(\mathbf{P P})\left({ }^{\circ} \mathbf{C}\right)$ & $\boldsymbol{T}_{\mathrm{c}}(\mathbf{P P})\left({ }^{\circ} \mathbf{C}\right)$ \\
\hline MBK/Hemp 60/40 $(\mathbf{B})$ & 15.2 & 1,270 & & \\
\hline B80PP20 & 22.1 & 1,360 & 158.2 & 111.7 \\
\hline B80PP18PPgMA2 & 20.2 & 1,150 & 153.7 & 114.0 \\
\hline B80PP15PPgMA5 & 22.3 & 1,600 & 160.4 & 120.0 \\
\hline B80PP10PPgMA10 & 20.2 & 1,380 & 159.0 & 119.0 \\
\hline
\end{tabular}

\section{Conclusions}

The control of properties of natural fibers reinforced polymer composites strictly depends on the possibility of modifying the interfacial adhesion through the improvement of the fiber-matrix interactions. In this paper the effect of chemical modification of fibers, as well as the addition of compatibilizers containing reactive groups (PP-g-GMA, SEBS- $g$-MA, PS-co-MA, EVA- $g$-MA, EVA-g-GMA, etc.), on the morphological, thermal and mechanical characteristics has been examined for PP, PS and EVA composites containing hemp, cellulose and oat. For all compatibilized systems, an 
enhanced fiber dispersion and interfacial adhesion has been observed, supporting the occurrence of effective interactions between the functional groups on the copolymer chains and the polar groups of the fibers, as demonstrated by FT-IR analysis. An increased thermal stability was found in PP composites with GMA modified hemp; moreover, marked changes in the morphology and overall crystallization rate of PP were observed in these composites due to the enhanced nucleating effect on the fiber surface. For all examined materials, the mechanical analysis showed that tensile modulus and elongation at break are significantly affected by the type and amount of fiber (aspect ratio: 10-20), as are affected by the structure (and concentration) of compatibilizer. In particular, the addition of functionalized polyolefins (PP-g-GMA, PS-co-MA) resulted in an increased stiffness owing to the improved fiber-matrix adhesion. In the case of PS/Cell composites, a higher interfacial adhesion was noticed in samples compatibilized with the block copolymer, SEBS-g-MA, as compared to those containing the random copolymer, PS-co-MA. This can be ascribed to the fact that the block copolymer is mostly located at the interface between filler particle and matrix, giving rise to more effective interactions with the polar groups of the fiber (Figure 19).

Figure 19. Effect of compatibilizer structure on the polymer-fiber interactions at the interface in PS/Cell composites.
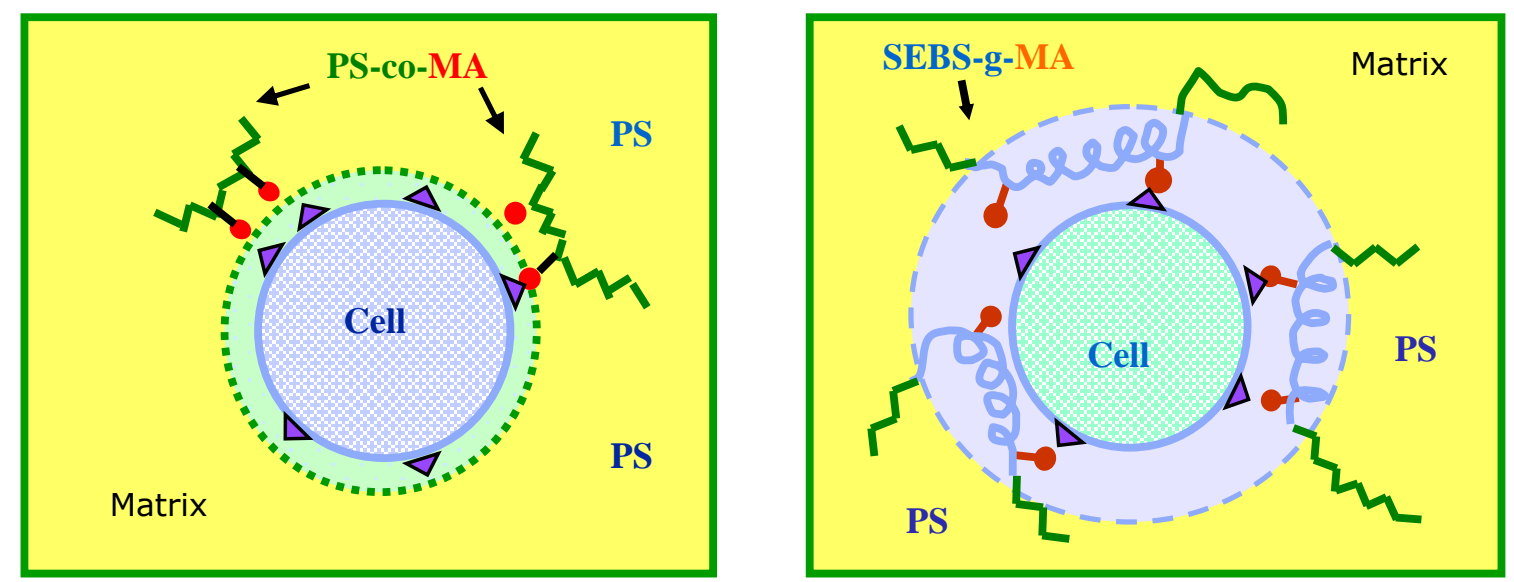

\section{Acknowledgements}

This research has been carried out within the framework of the Scientific Cooperation Agreements CNR-PAN (Poland) and CNR-CONICET (Argentina). The authors are very grateful to P. Narducci and I. Anguillesi, Department of Chemical Engineering, University of Pisa, for the SEM and DMTA analysis, and A. D'Alessio, Department of Chemistry and Industrial Chemistry, University of Pisa, for FTIR analyses.

\section{References}

1. Yu, L.; Dean, K.; Li, L. Polymer blends and composites from renewable resources. Prog. Polym. Sci. 2006, 31, 576-602.

2. Nabi Saheb, D.; Jog, J.P. Natural fiber polymer composites: A review. Adv. Polym. Technol. 1999, 18, 351-363. 
3. George, J.; Sreekala, M.S.; Thomas, S. A review on interfacial modification and characterization of natural fiber reinforced plastic composites. Polym. Eng. Sci. 2001, 41, 1471-1485.

4. Zafeiropoulos, N.E.; Williams, D.R.; Baillie, C.A.; Matthews, F.L. Engineering and characterisation of the interface in flax fibre/polypropylene composite materials. Part I. Development and investigation of surface treatments. Compos. A 2002, 33, 1083-1093.

5. Mwaicambo, L.Y.; Martuscelli, E.; Avella, M. Kapok/cotton fabric-Polipropilene composites. Polym. Test. 2000, 19, 905-918.

6. Lopez Machado, M.A.; Arroyo, M.; Biagiotti, J.; Kenny, J.M. Enhancement of mechanical properties and interfacial adhesion of PP/EPDM/flax fiber composite using maleic anhydride as a compatibilizer. J. Appl. Polym. Sci. 2003, 90, 2170-2178.

7. Rozman, H.D.; Kumar, R.N.; Abdul Khalil, H.P.S.; Abusamah, A.; Abu, R.; Ismail, H. Fibre activation with glycidyl methacrylate and subsequent copolymerization with diallyl phthalate. Eur. Polym. J. 1997, 33, 1213.

8. George, J.; Sreekala, M. S.; Thomas, S. A review on interfacial modification and characterization of natural fiber reinforced plastic composites. Polym. Eng. Sci. 2001, 41, 1471-1485.

9. Zhou, X.P.; Li, R.K.Y.; Xie, X.L.; Tjong, S.C. Reinforcement of polypropylene using sisal fibers grafted wiyh poly(methyl methacrylate). J. Appl. Polym. Sci. 2003, 88, 1055-1064.

10. Canchè-Escamilla, G.; Cauich-Cupul, J.I.; Mendizabal, E.; Puig, J.E.; Vazquea-Torres, H.; Herrera-Franco, P.J. Mechanical properties of acrylate-grafted henequen cellulose fibers and their application in composites. Compos. A 1999, 30, 349-359.

11. Rozman, H.D.; Saad, M.J.; Mohd Ishak, Z.A. Flexural and impact properties of oil palm empty fruit bunch (EFB)-polypropylene composites- the effect of maleic anhydride chemical modification of EFB. Polym. Test. 2003, 22, 335-341.

12. Gassan, J.; Bledzki, A.K. The influence of fibre-surface treatment on the mechanical properties of jute-polypropylene composites. Compos. A 1997, 28, 1001-1005.

13. Feng, D.; Caulfiled, D.F.; Sanadi, A.R. Effect of compatibilizer on the structure-property relationships of kenaf-fiber/polypropylene composites. Polym. Compos. 2001, 22, 506-517.

14. Espert, A.; Camacho, W.; Karlson, S. Thermal and thermomechanical properties of biocomposites made from recycled cellulose and recycled polypropylene. J. Appl. Polym. Sci. 2003, 89, 2353-2360.

15. Pracella, M.; Chionna, D.; Anguillesi, I.; Kulinski, Z.; Piorkowska, E. Functionalization, compatibilization and properties of polypropylene composites with hemp fibres. Comp. Sci. Technol. 2006, 66, 2218-2230.

16. Pracella, M.; Chionna, D. Reactive compatibilization of blends of PET and PP modified by GMA grafting. Macromol. Symp. 2003, 198, 161-171.

17. Mandelkern, L. Crystallization of Polymers; McGraw Hill: New York, NY, USA, 1964.

18. Wunderlich, B. Macromolecular Physics, Crystal Melting; Academic Press: New York, NY, USA, 1980; Volume 3.

19. Joseph, P.V.; Joseph, K.; Thomas, S.; Pillai, C.K.S.; Prasad, V.S.; Groeninckx, G; Sarkissova, M. The thermal and crystallization studies of short sisal fibre reinforced polypropylene composites. Compos. A 2003, 34, 253-266. 
20. Masirek, R.; Kulinski, Z.; Chionna, D.; Piorkowska, E.; Pracella, M. Composites of poly(Llactide) with hemp fibres: morphology, thermal and mechanical properties. J. Appl. Polym. Sci. 2007, 105, 255-268.

21. Hoffman, J.D.; Davis, G.T.; Lauritzen, J.I. The rate of crystallization of linear polymers with chain folding. In Treatise on Solid State Chemistry; Hannay, N.B., Ed.; Plenum Press: New York, NY, USA, 1976; Volume 3, Chapter 7.

22. Karnani, R.; Krishnan, M.; Narayan, R. Biofiber-reinforced polypropylene composites. Polym. Eng. Sci. 1997, 37, 476-483.

23. Tjong, S.C.; Xu, Y.; Meng, Y.Z. Composites based on maleated polypropylene and methyl cellulosic fiber: mechanical and thermal properties. J. Appl. Polym. Sci. 1999, 72, 1647-1653.

24. Lezak, E.; Kulinski, Z.; Masirek, R.; Piorkowska, E.; Pracella, M.; Gadzinowska, K. Mechanical and thermal properties of green polylactide composites with natural fillers. Macromol. Biosci. 2008, 8, 1190-1200.

25. Pracella, M.; Pancrazi, C.; D’Alessio, A.; Corti, A.; Chiellini, E. Property improvement and degradability control of polyolefin based composites containing natural fibres and mineral fillers. In Proceedings of the 13th Eur. Conf. on Composite Materials, ECCM13, Stochkolm, Sweden, June 2008; Proc. ID-2640.

26. Bellamy, L.J. The Infrared Spectra of Complex Molecules, 3rd ed.; Chapman and Hall: London, UK, 1975.

27. Pouchert, C.J. The Aldrich Library of Infrared Spectra; Aldrich Chemical Company, Inc.: Milwaukee, WI, USA, 1975.

28. Oksam, K.; Lindberg, H.; Holmgren, A. The nature and location of SEBS-MA compatibilizer in polyethylene-wood flour composites. J. Appl. Polym. Sci. 1998, 69, 201-209.

29. Yin, J.; Zhang, J.; Yao, Y. Melt grafting of poly(ethylene vinyl acetate) copolymer with maleic anhydride. J. Appl. Polym. Sci. 2006, 102, 841-846.

30. Henderson, M.A. Ethylene Vinyl Acetate (EVA) copolymers: A general review. IEEE Electron. Insul. Mag. 1993, 9, 30-38.

31. Dikobe, D.G.; Luyt, A.S. Morphology and properties of polypropylene/ethylene-vinyl acetate copolymer/wood powder blend composites. Express Polym. Lett. 2009, 3, 190-199.

32. Mydul, M.A.; Ahmed, T.; Haque, M.M.; Gafur, M.A.; Kabir, H.A.N.M. Mechanical properties of natural fibre containing polymer composites. Polym. Plast. Technol. 2009, 48, 10113.

33. Malunka, M.E.; Luyt, A.S.; Krump, H. Preparation and characterization of EVA-Sisal fibre composites. J. Appl. Polym. Sci. 2006, 100, 1607-1617.

34. Espert, A.; Vilaplana, F.; Karlsson, S. Comparison of water absorption in natural cellulosic fibres from wood and one-year crops in polypropylene composites and its influence on their mechanical properties. Compos. A. 2004, 35, 1267-1276.

35. Nakanishi, K. Infrared Absorption Spectroscopy; Holden-Day, Inc.: San Francisco, CA, USA, 1962; p. 44.

36. Pathan, L.A.; Oommn, Z.; Thomas, S. Dynamic mechanical analysis of banana fibre reinforced polyester composites. Compos. Sci. Technol. 2003, 63, 283-293. 
37. Alvarez, V.; Haque, M.M.; Ludueña, L.; Paci, M.; Pracella, M. Preparation and properties of biodegradable polymer/polyolefin-natural fibers ternary composites systems. In Proceedings of XII Latin American Symposium of Polymers, SLAP, San Jose, Costa Rica, July 2010; Proc. O-94.

(C) 2010 by the authors; licensee MDPI, Basel, Switzerland. This article is an open access article distributed under the terms and conditions of the Creative Commons Attribution license (http://creativecommons.org/licenses/by/3.0/). 